\title{
MENGKAJI NILAI SALAM DALAM AL-QUR'AN (KAJIAN TAFSIR TEMATIK)
}

\author{
Syamruddin Nasution ${ }^{1}$ dan Khoiruddin Nasution ${ }^{2}$ \\ ${ }^{1}$ Universitas Islam Negeri Sultan Syarif Kasim Riau, Indonesia \\ ${ }^{2}$ Universitas Islam Negeri Sunan Kalijaga Yogyakarta, Indonesia \\ syamruddinnst@gmail.com
}

\begin{abstract}
This article examines the value greeting the al-Qur'an through a approach to thematic tafsir. From a study conducted in the verses of the Qur'an greeting it can be seen that there is a meaningful greeting prayer, Such as petitioned Maryam to God to be saved in three the turn of life, i.e., at birth, at death and when you later in the future to God. There is also meaning of submitted greetings of Allah Subhanahu wa Ta'ala to His prophets, among other things, Nuh, Ibrahim, Musa, Harun, and Il-Yasin, including the prophet Muhammad that they have succeeded in carrying out their respective duties. Therefore, greeting value so high in the view of Islam. Forward, Prophet in a variety of his words ordered greeting is distributed among the Islamic community from the young to the old of the few to the lot, from which runs to sitting, from the drive is to the foot, from looking at who did not see, from students to teachers, from subordinates to superiors and others. There is also a greeting among the people Jahiliyah if they meet fellow friends, i.e., "Hayakallah" means hopefully your days long. In addition there is also greeting among the hypocrites that is based on their hostility to the prophet a greeting that is not taught by the Prophet told them i.e., "Assamu'alaikum" means may you be damned". This study uses thematic tafsir method, a description of the analysis of the verses of greeting as object the study of of the Qur'an. In this study found that high value greeting, should be used and disseminated among Muslims as prayer and congratulations on the success of those carrying out the task of a Muslim, lest greeting abused by the beggars so that the impression that the greeting of Islam belongs to the outskirts of the low value even though high value.
\end{abstract}

Key Words: The Value Greeting, al-Qur'an dan Thematic Tafsir

\begin{abstract}
Abstrak
Artikel ini mengkaji nilai salam dalam al-Qur'an melalui pendekatan tafsir tematik. Dari kajian yang dilakukan terhadap ayat-ayat salam dalam al-Qur'an dapat diketahui bahwa salam ada yang bermakna do'a, seperti yang dimohonkan Maryam kepada Allah agar selamat dalam tiga masa pergantian hidup, yaitu sewaktu dilahirkan, sewaktu dimatikan, dan sewaktu nanti kelak menghadap Allah. Ada juga bermakna ucapan selamat yang disampaikan Allah Subhanahu wa Ta'ala kepada para nabi-Nya, antara lain, nabi Nuh, Ibrahim, Musa, Harun dan Il-Yaasin, termasuk nabi Muhammad yang mereka sudah berhasil dalam menjalankan tugas masingmasing. Dengan demikian, nilai salam begitu tinggi dalam pandangan Islam. Seterusnya, Nabi dalam berbagai sabda-Nya memerintahkan agar salam disebarluaskan di kalangan masyarakat Islam dari yang muda kepada yang tua, dari yang sedikit kepada yang banyak, dari yang berjalan
\end{abstract}


kepada yang duduk, dari yang berkenderaan kepada yang berjalan kaki, dari yang melihat kepada yang tidak melihat, dari murid kepada guru, dari bawahan kepada atasan, dan lain sebagainya. Juga terdapat salam di kalangan masyarakat Jahiliyah apabila mereka bertemu dengan sesama temannya, yaitu "Hayakallah" artinya semoga umurmu panjang. Selain itu, terdapat juga salam di kalangan orang munafiq yang didasari permusuhan mereka kepada nabi suatu salam yang tidak diajarkan Nabi kepada mereka, yaitu "Assamu'alaikum”, artinya semoga engkau celaka". Kajian ini menggunakan metode tafsir tematik, diskripsi analisis terhadap ayat-ayat salam yang dijadikan objek kajian dalam al-Qur'an. Dalam studi ini menemukan bahwa salam yang bernilai tinggi, semestinya dipergunakan dan disebarluaskan di kalangan umat Islam sebagai do 'a dan ucapan selamat di atas keberhasilan mereka melaksanakan tugas kehambaan, jangan sampai salam disalahgunakan oleh kalangan peminta-minta sehingga menimbulkan kesan bahwa salam dalam Islam milik orang pinggiran yang bernilai rendah padahal yang semestinya bernilai tinggi.

Kata Kunci: Nilai Salam, Al-Qur'an dan Tafsir Tematik

\section{Pendahuluan}

Salam adalah sesuatu yang bernilai tinggi dalam Islam. Hal itu dapat dilihat dari beberapa ayat al-Qur'an yang berbicara tentang hal tersebut. Tetapi yang terjadi kini di kalangan umat Islam Indonesia, sebaliknya. Ternyata salam tersebar luas di kalangan masyarakat bawah. Hal tersebut menimbulkan kesan bahwa salam adalah milik orang rendahan dan kalangan masyarakat bawah. Akibat yang muncul dari perilaku tersebut menyebabkan sebagian orang Islam malu mengucapkan salam, seakan tidak mau disebut orang kampungan.

Kalangan peminta-minta pun lebih yakin menjadikan salam sebagai sarana komunikasi mereka dalam meminta kepada objek sasaran, karena salam sebagai simbol agama akan lebih menggugah hati orang yang diminta untuk memberikan shadaqah dibandingkan memakai simbol lain, seperti "Selamat pagi" atau "Helo pak".

Karena salam disebarluaskan oleh kalangan masyarakat bawah, baik peminta-minta jalanan maupun yang datang ke rumah-rumah, menimbulkan kesan bahwa setiap ada orang yang mengucapkan salam seolah-olah dianggap ada orang yang sedang meminta-minta shadaqah.
Sampai-sampai ada kasus seseorang mertua datang dari kampung mengucapkan salam ke rumah menantunya, tidak ada di antara penghuni rumah yang menjawab.

Tulisan ini berusaha untuk mendesksipsikan; pertama, mengkaji nilai salam dalam al-Qur'an yang tidak disangsikan lagi nilainya yang tinggi, tetapi mengapa ada kecenderungan sebagian umat Islam tidak mau memakainya dalam berinteraksi dengan teman-temannya bahkan ada cendurung meninggalkannya. Hal tersebut dibahas melalui kajian tafsir tematik.

Kedua, peristiwa sejarah yaitu dalam sejarah peradaban Islam disebutkan bahwa fondasi awal nabi Muhammad membangun masyarakat di Madinah di awal beliau datang ke Yatsrib adalah menyebarluaskan salam, sebagaimana terdapat dalam pernyataan Rasulullah, beliau bersabda; artinya "Sebarkanlah salam, berikanlah makan dan tegakkan shalat di waktu malam sedang manusia lain terlelap tidur malam" (HR. Bukhari Muslim).

Pokok bahasan dalam kajian ini adalah; (1) mengkaji bagaimana nilai salam dalam alQur'an, (2) apa usaha yang dilakukan sehingga salam tersebar luas di kalangan umat Islam pada kalangan atas maupun kalangan bawah sehingga 
salam berhasil menjadi bagian dari adat istiadat umat Islam, (3) dalam sejarah bagaimana yang dilakukan nabi Muhammad Saw. menyebarkan salam di kalangan masyarakat Islam pada awal kedatangan beliau di Madinah, dan (4) apa relevansinya mempelajari dan mengetahui nilai salam dalam al-Qur'an bagi kehidupan masa kini di Indonesia dengan melakukan kontektualisasi. Sebab empat unsur inilah yang penting diketahui dalam mempelajari tafsir sejarah, baik peristiwa maupun pemikiran. ${ }^{1}$

Karena kajian ini adalah kajian tafsir tematik, maka pada dasarnya sumber data dalam kajian tafsir tematik adalah sumber pustaka, dalam kajian ini memakai tafsir al-Azhar dan tafsir alMishbah. Dalam kajian tafsir tematik terlebih dahulu menetapkan topik pembahasan yaitu "salam", kemudian menghimpun ayat-ayat yang berkaitan dengan topik dengan langkah pengumpulan data dimulai dari koleksi/akumulasi data, verifikasi data, interpretasi data dan terakhir penulisan. $^{2}$

Sistematika penulisan dalam kajian ini dimulai dari pendahuluan, setelah itu dibahas (1) mengkaji nilai salam dalam al-Qur'an dengan pendekatan tafsir tematik, (2) peran atau usaha apa yang perlu dilakukan sehingga salam tersebar luas dan menjadi adat istiadat bagi umat Islam Indonesia, (3) Mengkaji usaha-usaha yang dilakukan Nabi Muhammad Saw. dalam menyebarkan salam di kalangan umat Islam di awal kedatangannya ke Yastrib, dan (4) relevansi mempelajari dan mengetahui nilai salam dan

\footnotetext{
${ }^{1}$ Tiga masalah penelitian ini pada prinsipnya sudah mencakup lima objek yang sudah umum diketahui dalam objek penelitian kajian sejarah, yaitu peristiwa (what), orang yang melaksanakan (who), tempat kejadian (where), masa kejadian (when), dan mengapa peristiwa itu terjadi (why) (Taufik Abdullah, Sejarah dan Masyarakat [Jakarta: Pustaka Firdaus, 1987], 105). Dari hal ini subjek penelitian kajian ini termasuk dalam penelitian sejarah sosial, sebab subjek penelitian sejarah adalah politik, sosial, ekonomi, dan gejala alam (Dudung Abdurrahman, Metode Penelitian Sejarah [Jakarta: Logos Wacana Ilmu, 1999]).

${ }^{2}$ Badri Yatim, Historiografi Islam (Jakarta: Logos, 1997), 4; oleh Kuntowijoyo disebut (1) tahap heuristic, (2) tahap kritik atau verifikasi, (3) tahap interpretasi, dan (4) tahap historiografi (Kuntowijoyo, Metodologi Sejarah [Yogyakarta: Tiara Wacana, 1994], 98).
}

peristiwa menyebarluaskan salam tersebut bagi kehidupan sekarang ini di Indonesia kemudian pembahasan diakhiri dengan kesimpulan.

\section{Mengkaji Nilai Salam dalam al-Qur'an}

\section{a. Pengertian Salam}

Secara terminologi kata salam berasal dari bahasa Arab artinya salam sejahtera, damai, salam hormat seperti sampaikan salam saya kepadanya. ${ }^{3}$ Pengertian salam dalam al-Qur'an bermakna keselamatan atau jalan keselamatan, ${ }^{4}$ juga dimaknai perdamaian, menyerah diri dan tunduk, ${ }^{5}$ yang terbanyak di antaranya bermakna mengucapkan salam keselamatan. ${ }^{6}$

Dengan demikian, pengertian salam yang terdapat dalam Kamus Bahasa Indonesia dan yang disebutkan dalam al-Qur' an sama-sama bermakna salam sejahtera, salam perdamaian, salam kehormatan, yang berbeda dalam Kamus Bahasa Indonesia tidak ada makna menyerah diri dan tunduk sementara dalam al-Qur'an ditemukan kedua hal itu.

\section{b. Klasifikasi Ayat-Ayat Salam Dalam al- Qur'an}

Dalam al-Qur' an terdapat ayat-ayat tentang salam, di antaranya yang dipergunakan Allah untuk perdamaian bagi yang menyerah dalam peperangan, mengucapkan selamat kepada para Rasul-Nya, ucapan selamat kepada penduduk surga, dan dalam hadits-hadits Nabi terdapat perintah menyembarkan salam di kalangan umat Islam.

Kata salam dalam al-Qur'an di dalam berbagai bentuknya terdapat sebanyak 45 ayat. ${ }^{7}$ Jika diklasifikasikan terbagi kepada

\footnotetext{
${ }^{3}$ Tim Penulis, Kamus Besar Bahasa Indonesia (Jakarta: Balai Pustaka, 1998), 866.

${ }^{4}$ Q.S. al-Maidah 5:16.

${ }^{5}$ Q.S. an-Nahl, 16: 28; Q.S. an-Nisaa', 4: 91.

${ }^{6}$ Q.S. Maryam, 19: 33; Q.S. ash-Shaaffaat, 37: 76-82.

${ }^{7}$ Ali Audah, Konkordansi Qur'an; Panduan Kata Dalam Mencari Ayat Qur'an (Jakarta: Pustaka Litera AntarNusa, 1991), hlm. 578 .
} 
empat kata; 1) bentuk kata al-salama dalam empat ayat yaitu, Q.S. an-Nisaa', 4: 90-91; Q.S. an-Nahl, 16: 28; Q.S. an-Nahl, 16: 87. Dari empat ayat di atas dapat diketahui bahwa makna al-salama adalah perdamaian, menyerah diri, dan tunduk.

Bentuk kata salaamu, al-salaamu dan salaamun sebanyak 34 ayat, dua ayat di antaranya dipakai untuk menyebut surge darul salaam (Q.S. al-An'am, 6: 127 dan Q.S. Yunus, 10: 25) satu ayat untuk menyebutkan jalan keselamatan (Q.S. al-Maidah, 5: 16) satu ayat lagi untuk menyebut nama Allah yang bersifat al-salaam yakni Maha Memberi keselamatan (Q.S. al-Hasyr, 59: 23) selebihnya dipakai untuk mengucapkan salam keselamatan.

Di antara ayat-ayat yang mengucapkan salam keselamatan itu, dipergunakan Allah mengucapkan selamat kepada para RasulNya, antara lain, sebagai berikut; Ketika Maryam bersandar ke pohon kurma menahan sakit menjelang persalinan, Malaikat Jibril datang menghiburnya "Goyangkan pangkal pohon kurma itu ke arahmu, makan, minum dan senangkanlah hatimu". Kalau ada yang datang katakan: "Aku bernazar tidak bicara”. Ketika kaumnya melihat bayi digendongnya mereka menuduhnya telah berbuat zina, tetapi Maryam terdiam seribu bahasa sambil menunjuk bayinya. Maka ketika itu berbicaralah sang bayi menjelaskan jati dirinya dan berdo'a: "Salam sejahtera (semoga) dilimpahkan kepadaku pada hari kelahiranku, hari wafatku dan hari ketika aku hidup dibangkitkan kembali "(Q.S. Maryam, 19: 33).

Ketika Allah mengabulkan permohonan nabi Nuh a.s. agar menyelamatkannya dan pengikutnya dari bencana besar dan menenggelamkan orang lain (kafir) ketika dunia banjir besar. Maka Allah mengucapkan salam kepada nabi Nuh setelah selamat dari bencana besar itu sebagai pujian yang baik kepada-Nya untuk diabadikan bagi orang-orang yang datang kemudian; "Salam kesejahteraan dilimpahkan kepada Nuh di seluruh alam". "Demikianlah Kami memberikan balasan kepada orang-orang yang berbuat baik". Selanjutnya Allah memuji nabi Nuh a.s. "Sesungguhnya dia termasuk di antara hamba-hamba Kami yang beriman kemudian Kami tenggelamkan yang lain” (Q.S. ash-Shaaffaat, 37: 79-82).

Ketika nabi Ibrahim membenarkan mimpinya, dia dan anaknya Isma'il pasrah dan berserah diri kepada Allah, Ibrahim membaringkan anaknya, ketika akan menyembelih anaknya, Allah ganti dengan seekor Kibas, sungguh yang demikian itu suatu ujian yang berat. Maka Allah mengucapkan selamat kepada nabi Ibrahim setelah dapat melaksanakan uijian yang berat itu sebagai pujian yang baik kepada-Nya untuk diabadikan bagi orang-orang yang datang kemudian; "Salam kesejahteraan dilimpahkan atas Ibrahim". "Demikianlah Kami memberikan balasan kepada orang-orang yang berbuat baik”. Selanjutnya Allah Ta'ala memuji nabi Ibrahim a.s. "Sesungguhnya dia termasuk di antara hamba-hamba Kami yang beriman" (Q.S. ash-Shaaffaat, 37: 109-111).

Ketika Allah menyelamatkan nabi Musa, Harun dan kaumnya dari bencana besar (tidak ditenggelamkan Allah di laut merah). Maka Allah mengucapkan selamat kepada keduanya setelah selamat dari bencana besar itu sebagai pujian yang baik kepada kedua-Nya untuk diabadikan bagi orang-orang yang datang kemudian; "Salam kesejahteraan dilimpahkan atas Musa dan Harun”. Selanjutnya Allah memuji keduanya "Sesungguhnya keduanya termasuk di antara hamba-hamba Kami yang beriman" (Q.S. ash-Shaaffaat, 37: 120-122).

Seperti itulah halnya kepada nabi Il-Yaasin, ketika dia sukses dalam tugasnya maka Allah mengucapkan selamat kepadanya. "Salam sejahtera atas Il-Yaasin, sesungguhnya 
demikianlah Kami memberikan ganjaran atas orang-orang yang berbuat kebajikan, Sesungguhnya dia termasuk di antara hambahamba Kami yang beriman" (Q.S. ashShaaffaat, 37: 130-132).

Juga dipergunakan Allah mengucapkan selamat kepada hamba-Nya yang berhasil menjadi penduduk surga "Maka keselamatanlah bagimu karena kamu dari golongan kanan" (Q.S. al-Waqi'ah, 56: 91). "Kepada mereka penduduk surga diucapkan salam, sebagai ucapan selamat dari Tuhan yang Maha Esa” (Q.S. Yaasiin, 36: 58).

Selain kata "Salam" terdapat juga kata "Hayu” dalam al-Qur'an yang menunjuk kepada salam karena masyarakat Jahiliyah dulu apabila bertemu sesama temannya mereka memberi hormat mengucapkan "Hayakallah", "moga-moga hidupmu dipelihara Allah". Dalam al-Qur' an terdapat kata "Hayu" untuk salam, sebagaimana firman-Nya; artinya "Apabila kamu dihormati dengan suatu penghormatan maka balaslah penghormatan itu dengan yang lebih baik atau balaslah dengan yang serupa sesungguhnya Allah memperhitungkan segala sesuatu” (Q.S. anNisaa', 4: 86). Juga terdapat di ayat lain untuk menjelaskan salam Yahudi munafiq kepada Nabi, sebagaimana firman-Nya; artinya "Dan apabila mereka datang kepadamu mereka mengucapkan salam kepadamu tidak dengan salam yang ditentukan Allah untukmu” (Q.S. al-Mujaadalah, 58: 8).

Dari kajian ayat-ayat tentang salam yang dikemukakan di atas dapat diketahui bahwa terdapat beberapa makna salam dalam alQur'an, yaitu perdamaian, menyerah diri, tunduk, nama surga, nama bagi Allah dan salam keselamatan walaupun sebenarnya perdamian, menyerah diri, tunduk adalah jalan untuk mendapat keselamatan dan yang terbanyak dari ayat-ayat salam itu bermakna mengucapkan salam keselamatan.

\section{c. Nilai Salam dalam al-Qur'an}

Berikut ini akan dikaji nilai salam dalam al-Qur'an dari ayat-ayat yang bermakna mengucapkan salam keselamatan, lebih khusus akan dibahas beberapa ayat yang sudah dikemukakan di atas dengan memakai dua tafsir, yaitu tafsir al-Azhar dan tafsir alMishbah sebagai berikut;

1. Salam Kesejahteraan Kepada Maryam

"Dan salam kesejahteraan semoga dilimpahkan kepadaku pada hari aku dilahirkan pada hari aku meninggal dan pada hari aku dibangkitkan hidup kembali” (Q.S. Maryam, 19: 33).

Hamka menjelaskan bahwa nabi Isa al-Masih bermohon kepada Allah agar diselamatkan dalam tiga pergantian hidup; yaitu (1) hari dia mulai hidup di dunia, (2) hidup di alam kubur sesudah mati, dan (3) hidup di hari kiamat sewaktu dibangkitkan Allah kembali. ${ }^{8}$ Hamka tidak menjelaskan lebih lanjut mengapa nabi Isa memohon keselamatan pada tiga pergantian hidup tersebut.

M. Quraish Shihab menjelaskan lebih lanjut bahwa salam sejahtera semoga tercurah atas diriku serta terhindar dari segala bencana dan kekurangan pada hari aku dilahirkan dan pada hari aku wafat, dan pada hari aku dibangkitkan kembali pada padang mahsyar kelak. ${ }^{9}$ Karena pada tiga tempat tersebut adalah tempat penting lagi genting dalam kehidupan manusia. Saat kelahiran, jika lahirnya cacat maka kehidupannya di dunia akan terganggu. Saat kematian, jika kematiannya meninggalkan dunia kurang atau tidak ada amal kebajikan maka kesengsaraan hidup akan menyertainya di

${ }^{8}$ Hamka, Tafsir Al-Azhar, Jilid XVI (Jakarta: PT Pustaka Panjimas, 1999), 29.

${ }^{9}$ M. Quraish Shihab, Tafsir Al-Mishbah, Jilid 8 (Jakarta: Lentera Hati, 2005), 180. 
alam barzah, dan perlunya keselamatan di padang mahsyar agar terhindar dari rasa malu dan takut yang mencekam. ${ }^{10}$

Dari dua penafsiran di atas dapat diketahui bahwa salam kesejahteraan pada tiga tempat pergantian hidup adalah do'a nabi Isa al-Masih kepada Allah. Jadi nabi Isa bermohon kepada Allah agar segala salam kesejahteraan dan kedamaian semoga tercurah kepadanya pada tiga tempat tersebut. Hal ini menjadi permintaan semua orang. Maka nilai salam dalam ayat tersebut sangat tinggi karena nabi Isa sebagai seorang Nabi yang memohon kepada Allah. Demikian juga hendaknya semua kaum muslimin selamat pada tiga tempat tersebut.

2. Salam Kesejahteraan kepada nabi Nuh "Salam kesejahteraan dilimpahkan kepada Nuh di seluruh alam”. "Demikianlah Kami memberikan balasan kepada orang-orang yang berbuat baik". Selanjutnya Allah memuji nabi Nuh a.s. "Sesungguhnya dia termasuk di antara hamba-hamba Kami yang beriman kemudian Kami tenggelamkan yang lain" (Q.S. AshShaaffaat, 37: 79-82).

Hamka menjelaskan bahwa ayat di atas adalah lanjutan kisah dari ayat sebelumnya pada saat nabi Nuh memohon kepada Allah menghancurkan orang-orang kafir kecuali hamba-hamba Allah yang tidak berdosa maka tidak dikaramkan. Maka ayat di atas, Allah mengucapkan selamat dan penghargaan yang sangat tinggi kepada nabi Nuh yang telah dengan gigih dan tabah dengan usia panjang menyampaikan peringatan Allah kepada kaumnya. ${ }^{11}$

${ }^{10}$ Ibid., 162.

${ }^{11}$ Hamka, Tafsir Al-Azhar, Jilid XXIII (Jakarta: PT Pustaka Panjimas, 1999), 128.
M. Quraish Shihab menyatakan selamat atas nabi Nuh adalah keterhindaran dari segala yang tercela dan berbahaya atau hal-hal yang tidak menyenangkan dan menakutkan seseorang pada tempat tertentu. Penggunaan kata nakirah pada salam yakni tidak memakai alif dan lam untuk menggambarkan betapa besar dan banyaknya keselamatan dan kedamaian yang diterima nabi Nuh. Karena nabi Nuh-lah orang pertama yang bangkit mengajarkan tauhid dan menumpas kemusyrikan dalam waktu yang lebih kurang seribu tahun. ${ }^{12}$ Dalam hal ini Allah mengucapkan selamat kepada nabi Nuh atas jasanya yang sangat besar di bidang dakwah tauhid.

3. Salam Kesejahteraan kepada nabi Ibrahim "Salam kesejahteraan dilimpahkan atas Ibrahim". "Demikianlah Kami memberikan balasan kepada orangorang yang berbuat baik”. Selanjutnya Allah memuji nabi Ibrahim a.s. "Sesungguhnya dia termasuk di antara hamba-hamba Kami yang beriman" (Q.S. ash-Shaaffaat, 37: 109-111).

Hamka menjelaskan bahwa penghargaan yang lebih tinggi Allah berikan kepada nabi Ibrahim karena nabi Ibrahim dapat selamat dalam pertempuran dahsyat di antara dua cinta; cinta kepada Allah dan cinta kepada anak. Pendiriannya yang tegar melaksanakan perintah Allah pada satu sisi dan pendiriannya yang tenang dan cintanya kepada anak pada sisi lain, dia tidak memaksakan kehendak kepada anak tetapi menginsafkannya.

Dia tidak ragu-ragu dan tidak bimbang menghadapi semua resiko. Dengan sukses beliau dapat melaksanakan perintah Allah

${ }^{12}$ M. Quraish Shihab, Tafsir Al-Mishbah, Jilid 12 (Jakarta: Lentera Hati, 2005), 50. 
dan anaknya selamat dari penyembelihan setelah digantikan Allah dengan seekor Kibas. Oleh karena penyerahan dirinya yang begitu tinggi kepada Allah maka datanglah ucapan selamat dan pujian yang tinggi dari Allah kepadanya. ${ }^{13}$

M. Quraish Shihab tidak menyebutkan sama sekali tentang ucapan selamat yang Allah berikan kepada nabi Ibrahim melainkan secara panjang lebar membahas tentang siapa yang disembelih Ibrahim antara dua anaknya; Isma'il atau Ishaq. ${ }^{14}$

Dari kisah di atas dapat diketahui bahwa apresiasi dan ucapan selamat yang tinggi datang dari Allah kepada nabiNya yang telah selesai melaksanakan ujian yang sangat berat dan penyerahan yang begitu tinggi pula kepada Allah. Demikianlah tingginya nilai salam yang Allah ucapkan kepada nabi-Nya Ibrahim.

4. Salam Kesejahteraan kepada nabi Musa dan Harun

"Salam kesejahteraan dilimpahkan atas Musa dan Harun"Selanjutnya Allah memuji keduanya "Sesungguhnya keduanya termasuk di antara hambahamba Kami yang beriman" (Q.S. ash-Shaaffaat, 37: 120-122).

Hamka menyatakan bahwa selamat sejahtera atas nabi Musa dan Harun itulah sebagai ucapan penghormatan tertinggi yang telah diberikan Allah dan dipujikanNya kepada kedua nabi yang berjasa tersebut karena mereka telah berjuang menghadapi seorang Raja yang zalim, yaitu Fir'aun yang merasa dirinya sangat tinggi dan bahkan mengaku sebagai tuhan dan tidak mau menerima ajaran nabi Musa

${ }^{13}$ Hamka, Tafsir Al-Azhar, Jilid XXIII (Jakarta: PT Pustaka Panjimas, 1999), 145-146.

${ }^{14}$ M. Quraish Shihab, Tafsir Al-Mishbah, Jilid 12 (Jakarta: Lentera Hati, 2005), 68-69. yang mengatakan bahwa hanya ada satu Tuhan yaitu Allah yang menguasai seluruh alam. ${ }^{15}$

Sesungguhnya mereka berdua termasuk di antara hamba-hamba Kami yang beriman . Iman yang sangat teguh, keyakinan yang tidak dapat digoyangkan, perjuangan yang tidak patah yang menyebabkan mereka berhasil memperoleh kemenangan yang gilang gemilang.

M. Quraish Shihab juga tidak lagi membahas tentang ucapan salam sejahtera yang disampaikan Allah kepada nabi Musa dan Harun, dapat diperkirakan karena Allah sudah berulangkali mengucapkan salam kepada Rasul atau Nabi-Nya sebelum keduanya yang mereka berjuang dalam menyampaikan misi kerasulannya. ${ }^{16}$

5. Salam Kesejahteraan kepada nabi IlYaasin

"Salam sejahtera atas Il-Yaasin, sesungguhnya demikianlah Kami memberikan ganjaran atas orangorang yang berbuat kebajikan, Sesungguhnya dia termasuk di antara hamba-hamba Kami yang beriman" (Q.S. ash-Shaaffaat, 37: 130-132).

Hamka menjelaskan selanjutnya demikianlah pujian-pujian Allah kepada Rasul-Nya Il-Yaasin, dia diakui sebagai seorang yang berjasa dalam kerasulannya. Oleh karena itu, patutlah kiranya nabi Il-Yaasin mendapatkan ganjaran dan penghargaan yang besar pula dari Allah karena dari dasarnya Allah tidak pernah lupa atas jasa orang yang berjasa. ${ }^{17}$

Sama seperti di atas M. Quraish

\footnotetext{
${ }^{15}$ Hamka, Tafsir Al-Azhar, Jilid XXIII (Jakarta: PT Pustaka Panjimas, 1999), 155.

${ }^{16}$ M. Quraish Shihab, Tafsir Al-Mishbah, Jilid 12 (Jakarta: Lentera Hati, 2005), 68-69.

${ }^{17}$ Hamka, Tafsir Al-Azhar, Jilid XXIII (Jakarta: PT Pustaka Panjimas, 1999), 159.
} 
Shihab tidak juga lagi membahas tentang ucapan salam sejahtera yang disampaikan Allah kepada nabi Il-Yaasin, dapat diperkirakan karena Allah sudah berulang kali mengucapkan salam kepada Rasul atau Nabi-Nya sebelumnya yang mereka berjuang dalam menyampaikan misi kerasulannya. ${ }^{18}$

6. Salam Kesejahteraan kepada nabi Muhammad Saw

Allah juga menyampaikan selamat kepada nabi Muhammad Saw. sewaktu Isra' Mi'raj ketika Allah bertemu dengan Rasulullah di langit yang ketujuh sebagai pujian yang baik kepada-Nya untuk diabadikan bagi orang-orang yang datang kemudian; "Salam kesejahteraan dilimpahkan atasmu wahai nabi beserta rahmat dan keberkatan dari Allah". Ucapan salam itulah kemudian yang diucapkan umat nabi Muhammad setiap mereka shalat dalam bacaan tahiyat awal dan tahiyat akhir, dia dijadikan dari salah satu rukun shalat, yaitu membaca tahiyat akhir yang di dalamnya ada ucapan salam.

7. Salam Kesejahteraan Kepada Penduduk Surga

"Maka keselamatanlah bagimu karena kamu dari golongan kanan” (Q.S. alWaqi'ah, 56: 91).

Hamka menjelaskan bahwa Allah mengucapkan selamat kepada penduduk surga yang telah memperoleh kesenangan dan nikmat surga karena mereka sudah istirahat dari sebelumnya yang membanting tulang dalam kehidupan dunia atau istirahat dari kebisingan dunia. Di surga mereka disambut Malaikat sambil berkata; "Wahai roh yang baik dan orang yang

${ }^{18}$ M. Quraish Shihab, Tafsir Al-Mishbah, Jilid 12 (Jakarta: Lentera Hati, 2005), 76. baik, selamat datang kami menyambutmu dengan kesenangan dan Allah menerima kedatanganmu dengan ucapan selamat datang dan dengan segenap kesenangan sebagai ganjaran atas upaya mereka mempertahankan jalan kanan". ${ }^{19}$

M. Quraish Shihab menjelaskan bahwa Allah mengucapkan selamat kepada penduduk surga yang telah memperoleh ketenangan lahir dan ketenteraman batin dalam kehidupan yang abadi, beristirahat dan tidak akan mati dalam kemuliaan dan ketinggian derajat bagi ashabul yamin. ${ }^{20}$

8. Ucapan Selamat Juga Kepada Penduduk Surga

"Kepada mereka penduduk surga diucapkan salam, sebagai ucapan selamat dari Tuhan yang Maha Esa", (Q.S. Yaasiin, 36: 58).

Hamka menjelaskan untuk mereka yang ada di dalam surga ada buah-buahan, bahkan segala buah-buahan segar yang berbagai macam, dan untuk mereka tersedia apa saja yang mereka pesan, apa saja yang mereka ingini dari segala macam kesenangan, sampai kepada anggur yang tidak memabukkan, semuanya tersedia. Maka Allah mengucapkan "Selamat Sejahtera" dan "selamat Datang" wahai ahli-ahli surga, kedatangan mereka disambut oleh Allah dan sebagaimana juga mereka disambut oleh malaikatmalaikat penjaga surga. ${ }^{21}$

M Quraish Shihab menjelaskan "Salamun" artinya kedamian agung sebagai ucapan dari Allah Tuhan Yang Maha Agung dan Yang Maha Penyayang

\footnotetext{
${ }^{19}$ Hamka, Tafsir Al-Azhar, Jilid XXVII (Jakarta: PT Pustaka Panjimas, 1999), 261-262.

${ }^{20}$ M. Quraish Shihab, Tafsir Al-Mishbah, Jilid 13 (Jakarta: Lentera Hati, 2005), 583-584.

${ }^{21}$ Hamka, Tafsir Al-Azhar, Jilid XXIII (Jakarta: PT Pustaka Panjimas, 1999), 55-56.
} 
yang tercurah kepada para penghuni surga. Makna keselamatan terhindar dari segala yang tercela, mereka mendapatkan sesuatu yang menyenangkan dan yang didambakan. $^{22}$

Dari kisah-kisah di atas dapat diketahui bahwa di antara Nabi itu, ada yang memohon salam keselamatan kepada Allah seperti nabi Isa memohon keselamatan kepada Allah pada tiga pergantian kehidupan. Itu artinya dari Nabi memohon keselamatan kepada Allah. Sedangkan pada Rasul-rasul yang lain, seperti nabi Nuh, Ibrahim, Musa, Harun, Il-Yaasin dan penduduk surga, justru Allah yang mengucapkan selamat kepada mereka atas jasa-jasa mereka memperoleh sukses dalam perjuangan hidup masing-masing. Hal ini menjadi bukti nyata bahwa ucapan salam kesejahteraan atau salam kedamaian sangat bernilai tinggi dalam Islam.

Dari kisah-kisah para Rasul di atas juga dapat dipahami bahwa salam tersebut dipergunakan Allah untuk mengucapkan selamat kepada para Rasul dan bahkan penghuni surga yang selamat dalam perjuangan mereka. Oleh karena itu, jangan lagi menyalahgunakan salam dijadikan sebagai alat untuk meminta-minta shadaqah kepada orang lain karena dengan berperilaku seperti itu akan merendahkan nilai salam.

Juga melalui kisah-kisah para Rasul di atas dihimbau kepada kaum muslimin kalangan atas dan terpandang agar ikut serta memasyarakatkan salam agar muncul kesan bahwa mengucapkan salam itu bernilai tinggi dalam pandangan Islam karena selalu diucapkan oleh masyarakat terpandang.

\section{Usaha-usaha Nabi Menyebarkan Salam}

Perkembangan berikutnya dalam sejarah peradaban Islam disebutkan bahwa fondasi awal

${ }^{22}$ M. Quraish Shihab, Tafsir Al-Mishbah, Jilid 11 (Jakarta: Lentera Hati, 2005), 560. nabi Muhammad membangun masyarakat madani di awal beliau datang di Yatsrib adalah salam. Dalam pernyataannya Rasulullah bersabda; artinya "Sebarkanlah salam atas orang yang engkau kenal dan yang tidak engkau kenal, berikanlah makan dan tegakkan shalat sedang manusia lain terlelap tidur" (HR. Bukhari Muslim).

Urgensi dan pentingnya salam disebarluaskan adalah untuk terjadi saling mendo'akan antara satu orang muslim dengan orang muslim lainnya, lewat saling mendo'akan akan terjalin silaturrahmi, dari silaturrahmi akan muncul rasa kasih sayang dan masyarakat yang dibingkai dengan kasih sayang akan tercipta masyarakat madani terjauh dari saling bermusuhan dan pertikaian.

Hal seperti itu tergambar dari kalangan masyarakat Yatsrib sebelum kedatangan nabi Muhammad Saw. yang penuh dengan permusuhan antara kaum Arab suku Aus dan Khazraj dengan kaum Yahudi suku bani Nadhir, bani Quraizah dan bani Qainuqa'. Akhirnya mereka menjadi masyarakat madani yang dibingkai rasa kasih sayang, antara lain, lewat bingkai salam.

Maka kepada kaum muslimin yang ada di Yatsrib diserukan Nabi agar mereka menyebarluaskan salam, untuk terjalin silaturrahmi dan saling mendo'akan dan terpancarlah sinar kasih sayang di antara sesama anggota masyarakat di Yatsrib sehingga tercipta masyarakat madani terhindar dari pertikaian dan permusuhan.

Selanjutnya Allah memerintahkan dalam firman-Nya "Apabila kamu dihormati dengan suatu penghormatan maka balaslah penghormatan itu dengan yang lebih baik atau balaslah dengan yang serupa sesungguhnya Allah memperhitungkan segala sesuatu” Q.S. an-Nisaa', 4: 86).

Hamka menjelaskan membalas hormat dengan yang lebih baik artinya kalau orang mengucapkan "Assalamu'alaikum” balaslah dengan “Wa'alaikumus Salam wa Rahmatullah”. Dan kalau salam itu ditambahkan lagi dengan 
“Warahmatullah” balaslah dengan tambahan lagi “Wabarakatuh”. ${ }^{23}$

Dulu, masyakarat jahiliyah kalau bertemu dengan kawannya, dia memberi hormat dengan ucapan "Hayakallah" Moga-moga hidupmu dipelihara Allah atau kalau dalam istilah sekarang "Semoga umurmu panjang". ${ }^{24}$ Hal itu samalah dengan yang terjadi di tengah-tengah masyarakat Indonesia, terutama di awal kemerdekaan dahulu apabila mereka bertemu sesama teman mereka mengucapkan "Hidup Bung” sebagai tanda hormat. Kemudian berkembang menjadi Selamat Pagi, Selamat Siang, Selamat Sore, dan Selamat Malam sebagai tanda penghormatan. Sedangkan salam yang dikenal di Tapanuli "Horas Bah" juga sebagai tanda penghormatan. Sedangkan salam di Jawa khususnya Yogyakarta "Pie Kabare" atau apa kabarnya, sebagai tanda hormat.

Sama seperti Hamka, M. Quraish Shihab juga membahas tentang salam di masa Jahiliyah apabila mereka bertemu, saling mengucapkan salam, antara lain yang berbunyi "Hayakallah" artinya semoga Allah memberikan untukmu kehidupan. Maka kata "Hayu” dalam ayat di atas dipahami dalam arti mengucapkan salam. ${ }^{25}$

Dalam Islam diganti ucapan salam masyarakat Jahiliyah tersebut dengan "Assalamu'alaikum”. Maka dalam integrasi sosial di tengah-tengah masyarakat, Allah dan Rasul-Nya berpesan agar menyebarluaskan salam kedamaian antara seluruh anggota masyarakat, kecil atau besar, dikenal atau tidak dikenal. Ketika Nabi ditanya bagaimana praktik salam kedamaian dalam Islam, beliau bersabda "Memberikan pangan dan mengucapkan salam kepada yang anda kenal dan yang tidak anda kenal" (HR. Bukhari Muslim). ${ }^{26}$

Ucapan yang diajarkan dan dianjurkan dalam Islam bukan hanya mengucapkan "Assalamu'alaikum”, tetapi juga ditambah lagi

\footnotetext{
${ }^{23}$ Hamka, Tafsir Al-Azhar, Jilid V (Jakarta: PT. Pustaka Panjimas, 1999), 239.

${ }^{24}$ Ibid.

${ }^{25}$ M. Quraish Shihab, Tafsir Al-Mishbah, Jilid 2 (Jakarta: Lentera Hati, 2005), 538.

${ }^{26}$ Ibid.
}

dengan "Warahmatullah" dan "Wabarakatuh". Itu artinya bukan hanya keselamatan dari kekurangan yang diharapkan kepada mitra salam kita tetapi juga rahmat Allah dan berkah-Nya tercurah dengan aneka ragam kebajikan-Nya. ${ }^{27}$

Pengucap salam sesuai dengan diajarkan dan dianjurkan dalam Islam adalah mengucapkan “Assalamu'alaikum” dinilai Nabi memperoleh sepuluh ganjaran, bila ditambah dengan "Warahmatullah" menjadi dua puluh dan apabila disertai lagi dengan "Wabarakatuh" genaplah ganjarannya menjadi tiga puluh. ${ }^{28}$

Dari hadis-hadis yang disebutkan di atas dapat diketahui begitu tingginya nilai salam, selain memohon keselamatan kepada mitra salam kita, juga pengucap salam akan mendapat pahala dari Allah, mulai dari sepuluh ganjaran sampai tiga puluh ganjaran, dia tergantung dari pendek panjangnya salam yang diucapkan.

Sementara di kalangan orang Munafiq terdapat lagi ucapan salam kepada Nabi dan umat Islam yang berbeda dengan Islam, yaitu "Assamu'alaikum” sebagaimana dijelaskan Allah dalam al-Qur'an; “...Dan apabila mereka datang kepadamu mereka mengucapkan salam kepadamu tidak dengan salam yang ditentukan Allah untukmu” (Q.S. al-Mujaadalah, 58: 8).

Hamka menjelaskan orang munafiq datang menemui Nabi didasari oleh dendam, permusuhan, dan kebencian mereka mengucapkan salam yang pada lahirnya memberi hormat padahal dalam batin mereka berisi penghinaan dan kutukan. Mereka memotong "lam" dari salam yang diajarkan Nabi kepada mereka, menjadi “Assamu'alaikum Ya Abal Qasim”. Lalu dijawab oleh A'isyah “Wa'alaikuum Saam” yang berarti kamupun celaka juga. ${ }^{29}$

Hal yang sama dijelaskan juga oleh $\mathrm{M}$. Quraish Shihab bahwa orang munafiq mengucapkan salam kepada nabi dengan

\footnotetext{
${ }^{27}$ Ibid.

${ }^{28}$ Ibid., 539.

${ }^{29}$ Hamka, Tafsir Al-Azhar, Jilid XXVIII (Jakarta: PT. Pustaka Panjimas, 1999), 22.
} 
mengganti kata "Assalamu'alaikum” menjadi "Assamu'alaikum”, maknanya "kematian untuk kamu" yang mengandung kata pelecehan dan do'a agar nabi ditimpa bencana. ${ }^{30}$

Oleh karena itu, terdapat hadis Nabi yang melarang kaum muslimin mengucapkan salam kepada orang Yahudi dan Nashrani (HR. Muslim dari Abu Hurairah) karena permusuhan mereka kepada umat Islam. Tetapi banyak ulama yang membolehkan memulai ucapan salam kepada non-Islam, antara lain, Ibn Abbas karena larangan nabi mereka pahami dalam konteks zamannya. Kalaupun ada orang Yahudi munafiq yang mengucapkan salam "Assamu'alaikum” yang berarti kutukan untuk kamu, boleh dibalas atau dijawab dengan "Alaikum”. Kata "Alaikum” tanpa " $W a$ " itu artinya kutukan itu untuk kalian bukan untuk kami. ${ }^{31}$ Imam Malik juga menfatwakan kalau Ahlul Kitab mengucapkan salam maka bolehlah salamnya itu dijawab dengan "Alaika" atau "Alaikum". ${ }^{32}$ Kalau seperti di Indonesia, ucapan salam kepada yang non Muslim lebih baik memakai "Selamat Pagi atau Selamat Siang atau Selamat Sore dan atau Selamat Malam".

Perlu kiranya ditambahkan bahwa tata cara mengucapkan salam itu dimulai dari yang kecil kepada yang tua, yang sedikit kepada yang banyak, yang berjalan kepada yang duduk, yang berkenderaan kepada yang berjalan kaki, yang melihat kepada yang tidak melihat, dari murid kepada guru dari bawahan kepada atasan, dan lain-lain. ${ }^{33}$

Salam adalah salah satu di antara hak dan kewajiban orang Islam sesama Islam. Sebagaimana Nabi menyuruh orang Islam dengan tujuh perkara; (1) Menjenguk orang sakit, (2) Mengiringi jenazah, (3) Menjawab bersin, (4)

\footnotetext{
${ }^{30}$ M. Quraish Shihab, Tafsir Al-Mishbah, Jilid 14 (Jakarta: Lentera Hati, 2005), 73.

${ }^{31}$ M. Quraish Shihab, Tafsir Al-Mishbah, Jilid 2 (Jakarta: Lentera Hati, 2005), 539.

${ }^{32}$ Hamka, Tafsir Al-Azhar, Jilid XXVIII (Jakarta: PT Pustaka Panjimas, 1999), 23.

${ }^{33}$ M. Quraish Shihab, Tafsir Al-Mishbah, Jilid 2 (Jakarta: Lentera Hati, 2005), 541
}

Membela orang yang lemah, (5) Menolong orang yang teraniaya, (6) Menyebarluaskan salam, (7) dan Menebus sumpah (HR. Bukhari dan Muslim). ${ }^{34}$ Maka salam menjadi salah satu dari tiang kedamaian hidup.

Itu sebabnya salam disebut salam kesejahteraan dan salam kedamaian sehingga nabi bersabda; "Sesungguhnya perangai Islam yang paling mulia dan paling baik adalah memberi salam (menjamu) dan menyampaikan salam kepada orang yang engkau kenal dan kepada orang yang tidak engkau kenal" (HR. Bukhari dan Muslim). Oleh sebab itu, nabi menyuruh lagi untuk menyebarluaskan salam dengan sabdanya; "Sebarluaskanlah salam, niscaya akan timbul cinta mencintai di antara kamu"'(HR. al-Hakim). ${ }^{35}$

Dari hadis-hadis di atas dapat diketahui bahwa Nabi berulang-ulang menyampaikan dalam hadishadis yang berbeda agar salam disebarluaskan, itu artinya bahwa salam itu lambang kedamaian yang sangat perlu terwujud di kalangan umat Islam. Hal yang sama dilakukan Nabi pada waktu awal kedatangan beliau ke Madinah beliau berpidato di hadapan penduduk Madinah, artinya "Wahai sekalian manusia, sebarkanlah salam, hidangkanlah makanan, hubungkanlah kasih sayang, dan shalatlah di tengah malam, niscaya kamu semuanya akan masuk ke dalam surga dengan penuh kedamaian"36.

Selain dari itu, kepada semua kaum muslimin disediakan do'a memohon keselamatan setiap mereka selesai dari melaksanakan shalat agar mendapat kedamaian dalam menjalani kehidupan ini yaitu; "Allahumma antas salaam wa minkas salam wa ilaika ya'udus salam fa haiina Rabbanaa bis salam wa adkhilnal jannata daras salam, "artinya: "Ya Allah! Engkaulah keselamatan dan dari Engkau datang keselamatan dan kepadaMu kembali keselamatan maka hidupkalah kami

\footnotetext{
${ }^{34}$ Hamka, Tafsir Al-Azhar, Jilid V (Jakarta: PT. Pustaka Panjimas, 1999), 243.

${ }^{35}$ Hamka, Tafsir Al-Azhar, Jilid V (Jakarta: PT Pustaka Panjimas, 1999), 242.

${ }^{36}$ Ibid., 243-244.
} 
dalam keselamatan dan masukkanlah kami ke dalam surga Daras Salam" (HR. Muslim). Semoga lewat salam damailah kiranya kehidupan umat Islam.

\section{Relevansi Mempelajari dan Mengamalkan Nilai Salam Sekarang}

Dapat diketahui dan diperkirakan bahwa mungkin sebagian besar umat Islam Indonesia tidak begitu mengetahui makna yang terkandung di dalam salam, sampai berulang kali Nabi menyuruh untuk menyebarluaskan salam. Dari kajian yang telah dikemukakan di atas dapat diharapkan agar umat Islam Indonesia dapat mengetahui kandungan nilai yang terdapat dalam salam dan memahami rusuhan atau perintah Nabi Muhammad Saw. untuk menyebarluaskan salam. Dengan memahami hal tersebut akan dengan sendirinya umat Islam ikut berperan serta dalam menyebarluaskan salam kedamaian di kalangan umat Islam yang bernilai tinggi tersebut.

Saat ini salam masih tersebar luas di kalangan masyarakat bawah terkhusus para peminta-minta bukan untuk mendo'akan keselamatan kepada mitra salamnya, juga bukan untuk mengucapkan selamat atas prestasi mereka mencapai sukses dalam hidup ini sebagaimana yang semestinya salam dilakukan, tetapi untuk meminta-minta sesuatu. Hal ini berarti terjadi penyalahgunaan salam dari memohonkan keselamatan, rahmat dan keberkatan dan mengucapkan selamat menjadi untuk meminta-minta sesuatu.

Kaum muslimin mesti kembali ke jati diri mereka, menyebarluaskan salam untuk memohon keselamatan, rahmat, dan keberkatan juga mengucapkan selamat kepada mitra salam dan umat Islam secara keseluruhan. Hal ini dapat dimulai dari kalangan atas; para pejabat, orang terpandang, orang hartawan, orang besar, para artis sebagai idola masyarakat agar terbentuk opini masyarakat bahwa nilai salam itu tinggi dan milik semua orang Islam, termasuk orang-orang hebat.

Perlunya salam harus dimasyarakatkan orang-orang hebat supaya umat Islam tidak kalah bersaing dengan "Helo, Good Morning" yang dimasyarakatkan Bill Clinton atau Barack Obama dari "Gedung Putih". Memang diakui, kita kalah dalam membentuk opini publik. Kalau begitu menjadi suatu keharusan bagi umat Islam terutama kalangan atas untuk ikut serta secara aktif membentuk opini publik tentang tingginya nilai salam dan itu menjadi suatu keniscayaan.

\section{Kesimpulan}

Sebagai kesimpulan dari kajian yang telah dikemukakan di atas dapat dinyatakan bahwa salam tersebut; ada yang bermakna do'a kepada Allah meminta keselamatan pada tiga pergantian kehidupan (Q.S. Maryam, 19: 33), ada juga bermakna ucapan selamat Allah kepada; Nabi Nuh ketika diselamatkan dari banjir besar (Q.S. ash-Shaaffaat, 37: 79-82), Nabi Ibrahim (Q.S. ash-Shaaffaat, 37: 109-111), Nabi Musa dan Harun (Q.S. ash-Shaaffaat, 37: 120-122), Nabi Il-Yaasin (Q.S. ash-Shaaffaat, 37: 130-132), Nabi Muhammad Saw. (ketika Isra' Mi'raj), orang beriman yang telah selamat masuk surga (Q.S. al-Waqi'ah, 56: 9 dan Q.S. Yaasiin, 36: 58).

Semua salam tersebut di atas sangat bernilai tinggi, dari Allah kepada Rasul dan Nabi-Nya, juga orang beriman yang telah berhasil masuk surga sebagai ucapan keselamatan, kepada mereka yang telah berhasil menunaikan tugas masing-masing. Tingginya nilai salam perlu diketahui umat Islam agar masing-masing dari mereka merasa bertanggung jawab untuk menyebarluaskannya di kalangan umat Islam.

Nabi Muhammad Saw. dalam berbagai sabda-Nya telah menyatakan tentang tingginya nilai salam, anjuran menyebarluaskan salam, menjadikan salam sebagai bingkai pembangunan masyarakat Madinah di awal kedatangannya dan bahkan Nabi menjelaskan tata cara salam di tengah-tengah masyarakat.

Pada dasarnya mengucapkan salam yang disuruh Nabi untuk disebarluaskan dalam rangka mendo'akan keselamatan, diberi rahmat, keberkatan, pahala, dan ucapan selamat bagi 
yang berhasil dan sukses dalam kehidupan, tetapi dalam perkembangannya salam dipergunakan oleh sebagian umat Islam dalam rangka memintaminta sesuatu.

Dulu di kalangan masyarakat Jahiliyah telah ada salam penghormatan sebagai ucapan selamat, yaitu "Hayakallah", artinya semoga umurmu panjang, sedangkan di Indonesia terdapat ucapan "Selamat Pagi", Selamat Siang", "Selamat Sore" dan "Selamat Malam" sebagai penghormatan. Hal tersebut di atas diganti oleh Nabi Muhammad Saw. dengan ucapan "Assalamu'alaikum" sebagai do'a dan penghormatan.

Di kalangan Yahudi munafiq terdapat juga salam kepada nabi suatu salam yang tidak pernah diajarkan nabi kepada mereka yang didasari oleh rasa permusuhan dan dendam kesumat, yaitu “Assamu'alaikum”, artinya celakalah engkau ya Abal Qasim, sebagai tanda dendam dan permusuhan. Pada mulanya ada larangan Nabi mengucapkan salam kepada Ahlul Kitab ketika mereka memusuhi Islam tetapi dalam perkembangan zaman, banyak ulama yang membolehkan memulai ucapan salam kepada non-Islam, antara lain, Ibn Abbas.

Salam harus dimasyarakatkan orang-orang hebat dari kalangan atas supaya umat Islam tidak kalah bersaing dengan "Helo, Good Morning" yang dimasyarakatkan Bill Clinton atau Obama dari "Gedung Putih".

\section{Daftar Kepustakaaan}

Ali Audah. Konkordansi Qur'an; Panduan Kata Dalam Mencari Ayat Qur'an. Jakarta: Pustaka Litera AntarNusa, 1991.

Badri Yatim. Historiografi Islam. Jakarta: Logos, 1997.

Dudung Abdurrahman. Metode Penelitian Sejarah. Jakarta: Logos Wacana Ilmu, 1999.

Hamka. Tafsir Al-Azhar. Jilid V, XVI, XXIII, XXVII, dan XXVIII. Jakarta: PT Pustaka Panjimas, 1999.

Kuntowijoyo. Metodologi Sejarah. Yogyakarta: Tiara Wacana, 1994.

M. Quraish Shihab. Tafsir Al-Mishbah. Jilid 2, 8, 11, 12, 13, dan 14. Jakarta: Lentera Hati, 2005.

Taufik Abdullah. Sejarah dan Masyarakat. Jakarta: Pustaka Firdaus, 1987.

Tim Penulis. Kamus Besar Bahasa Indonesia. Jakarta: Balai Pustaka,1998. 